Fall 1983

\title{
Disaggregation in Deterrence and Death Penalty Research: The Case of Murder in Chicago
}

William C. Bailey

Cleveland State University, w.bailey@csuohio.edu

Follow this and additional works at: https://engagedscholarship.csuohio.edu/clsoc_crim_facpub

Part of the Criminology Commons

How does access to this work benefit you? Let us know!

Publisher's Statement

(c) 1983 University of Illinois Press

\section{Original Citation}

Bailey, W. C. (1983). Disaggregation in Deterrence and Death Penalty Research: The Case of Murder in Chicago. Journal Of Criminal Law \& Criminology, 74(3), 827-859.

\section{Repository Citation}

Bailey, William C., "Disaggregation in Deterrence and Death Penalty Research: The Case of Murder in Chicago" (1983). Sociology \& Criminology Faculty Publications. 71.

https://engagedscholarship.csuohio.edu/clsoc_crim_facpub/71

This Article is brought to you for free and open access by the Sociology \& Criminology Department at EngagedScholarship@CSU. It has been accepted for inclusion in Sociology \& Criminology Faculty Publications by an authorized administrator of EngagedScholarship@CSU. For more information, please contact library.es@csuohio.edu. 


\title{
DISAGGREGATION IN DETERRENCE AND DEATH PENALTY RESEARCH: THE CASE OF MURDER IN CHICAGO
}

\author{
William C. Bailey, Cleveland State University
}

This article was originally published in:

Bailey, William C. (1983). Disaggregation in Deterrence and Death Penalty Research: The Case of Murder in Chicago. The Journal of Criminal Law and Criminology, 74(3), 827-859.

Post-print standardized by MSL Academic Endeavors, the imprint of the Michael Schwartz Library at Cleveland State University, 2013

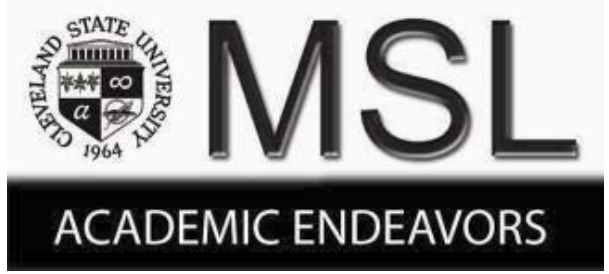




\title{
DISAGGREGATION IN DETERRENCE AND DEATH PENALTY RESEARCH: THE CASE OF MURDER IN CHICAGO
}

\author{
WILLIAM C. BAILEY*
}

\section{INTRODUCTION}

The proper role, if any, of capital punishment in our criminal justice system is an issue of unparalleled discussion in professional literature. Over one thousand books, articles, and reports on one or more aspects of the death penalty question have appeared since the turn of the century. In addition, the death penalty debate is not confined solely to professional circles; it occupies a prominent role in the popular press, media, and periodicals. In fact, the literature is so voluminous and the moral, legal, ethical, and empirical issues involved are so diverse and complex, that even the most recognized contemporary authorities on capital punishment readily acknowledge the limitations of their knowledge and understanding. ${ }^{1}$

The death penalty issue that is the focus of the greatest discussion and polarization both in professional and lay literature is the question of deterrence: does capital punishment deter crime, and most notably, murder? More properly and practically stated, does capital punishment provide a more effective general deterrent to murder than alternative legal sanctions such as imprisonment?

Social scientists-most notably sociologists and criminologistshave played a long and active role in addressing this question empirically, with all studies up until the mid-1970's rejecting the deterrence hypothesis for capital punishment. For example, over five decades of research in this country failed to show higher murder rates in abolition than death penalty states, an increase in the murder rate after some states abolished capital punishment, or a decrease in murder after some

* Professor of Sociology, Cleveland State University; Ph.D., Sociology, Washington State University, 1971; B.S., Central Washington State University, 1966.

1 H. Bedau, The Death Penalty in America (3d ed. 1982); T. Sellin, The Penalty OF DEATH (1980). 
jurisdictions reinstated the death penalty, all of which the deterrence hypothesis predicts. ${ }^{2}$ In addition, both longitudinal and cross-sectional examinations of actual execution rates and murder rates in retentionist jurisdictions failed to show a significant inverse relationship between these two factors as the deterrence hypothesis predicts. ${ }^{3}$

These studies, along with additional anecdotal information from noted prison wardens and chaplains, ${ }^{4}$ psychiatrists, ${ }^{5}$ and convicted murderers ${ }^{6}$ brought most social scientists to what Sellin has termed the "inevitable" conclusion that capital punishment, in either law or practice, has no discernible effect as a deterrent to murder. ${ }^{7}$ The prevailing opinion was expressed by Barnes and Teeters when they claimed that deterrence justifications for capital punishment are but "rationalizations of revenge."8

Despite the presumed conclusiveness of the evidence against the death penalty as a deterrent to murder, ${ }^{9}$ and the anti-capital punishment attitude held by most social scientists, the deterrence question became a lively area of debate in the professional literature during the middle of the last decade. At least four major factors appear to be responsible for the return of the deterrence question to prominence in the social science and legal literature during this period: ${ }^{10}(1)$ a growing theoretical and empirical interest in the general deterrence doctrine, which stemmed in large part from Gibbs' ${ }^{11}$ and Becker's ${ }^{12}$ critiques of the antipunishment and anti-deterrence attitudes held by many social scientists; (2) a growing awareness of the theoretical and methodological complex-

2 H. Bedau, The Death Penalty in America (rev. ed. 1967); R. Bye, Capital Punishment in the United States (1919); C. Kirkpatrick, Capital Punishment (1925); $T$. Sellin, The Death Penalty (1959); Dann, The Deterrent Effect of Capital Punishment, 29 Friends Soc. Serv. Rev, 1 (1935); Reckless, The Use of the Death Penalty, 15 Crime \& DELINQ. 43 (1969); Schuessler, The Deterrent Infuence of the Death Penally, 284 ANNals 54 (1952); Sutherland, Murder and the Death Penally, 15 J. AM. Inst. CRIM. L. \& CRIMINology 522 (1925); Vold, Can the Death Penaly Prevent Crime?, 12 PRISON J., Oct. 1932, at 4.

3 T. Sellin, Capitol Punishment (1967); Bailey, Murder and Capital Punishment: Some Further Evidence, 45 AM. J. ORTHOPSYCHIATRY 669 (1975); Schuessler, supra note 2.

4 C. Duffy \& A. Hirshberg, 88 Men AND 2 WOMEn (1962); L. LaWes, MaN's JudGMENT OF DEATH (1924).

5 D. J. West, Murder Followed by Suicide (1965).

6 C. Chessman, Cell 2455, Death Row (1954).

7 T. SELLIN, supra note 3, at 138 (1967).

8 H. E. Barnes \& N. Teeters, New Horizons in Criminology 355 (1951).

9 A contrary view cannot be found in a simple criminology textbook published in this country from the turn of the century up until the mid-1970's.

10 See generally, H. BEDAU, supra note 1; T. SEllin, supra note 1; Bailey, Delerrence and the Celerity of the Death Penally: A Neglected Question in Deterrence Research, 58 SOC. ForCES 1308 (1980); Gibbs, Preventive Effects of Capital Punishment Other Than Deterrence, 14 CRIM. L. BULL. 34 (1978).

11 Gibbs, Crime, Punishment, and Deterrence, 48 Sw. Soc. ScI. Q. 515 (1968).

12 Becker, Crime and Punishment: An Economic Approach, 76 J. POL. ECON. 169 (1968). 
ity of the deterrence issue and the serious shortcomings (both theoretical and methodological) of previous deterrence studies; (3) complaints by the United States Supreme Court in two important decisions ${ }^{13}$ about the lack of recent, clear-cut evidence on the deterrent effect of capital punishment; and (4) the publication of a highly controversial article by Isaac Ehrlich in 1975 which (a) dismissed as methodologically naive and meaningless over five decades of previous death penalty research, and (b), of equal importance, reported certainty of execution to be a very significant deterrent to murder. ${ }^{14}$ Examining national execution and homicide data for various periods between 1933 and 1969, Ehrlich concluded that "an additional execution per year over the period in question may have resulted on average, in 7 or 8 fewer murders."15 Moreover, in a study which followed soon after Ehrlich's and which used similar econometric techniques to examine national murder and execution data for various periods between 1933 and 1972, Yunker reached the conclusion that "one execution will deter 156 murders."16

While both Ehrlich's and Yunker's studies have come under intense scrutiny and are now considered totally discredited by most authorities, ${ }^{17}$ their work and the additional factors noted above brought to the forefront an awareness of the complexity of the deterrence question and the need for a more sophisticated methodology than was employed in earlier studies.

\section{Summary of REcent Research}

The mid-1970's saw a movement in research on the deterrent value of the death penalty away from the traditional practice of simply examining the bivariate relationship between (1) the presence or absence of capital punishment and variation in state homicide rates, and/or (2) the

13 Gregg v. Georgia, 428 U.S. 153 (1976); Furman v. Georgia, 408 U.S. 238 (1972).

14 Ehrlich, The Deterrent Effect of Capital Punishment: A Question of Life and Death, 65 AM. ECON. REv. 397 (1975).

15 Id. at 414.

16 Yunker, Is the Death Penalty a Deterrent to Homicide? Some Time Series Evidence, 5 J. BEHAV. ECON., Summer 1976, at 45.

17 See, e.g., Bowers \& Pierce, The Illusion of Deterrence in Isaac Ehrlich's Research on Capital Punishment, 85 YALE L.J. 187 (1975); Brier \& Fienberg, Recent Econometric Modeling of Crime and Punishment: Support for the Delerrence Hypothesis?, 4 Evaluation REv. 147 (1980); Forst, The Deterrent Effect of Capital Punishment: A Cross-Stale Analysis of the 1960's, 61 MINN. L. REV. 743 (1977); Friedman, The Use of Mulliple Regression Analysis to Test for a Deterrent Effect of Capital Punishment: Prospects and Problems, in 1 CRiminology Review Yearbook 61 (S. Messinger \& E. Bittner eds. 1979); Klein, Forst \& Filatov, The Deterrent Effect of Capital Punishment: An Assessment of the Estimates, in DETERRENCE AND INCAPACITATION: Estimating THE EFFEcTS of Criminal Sanctions on Crime Rates (A. Blumstein, J. Cohen \& D. Nagin eds. 1978); Passell \& Taylor, The Deterrent Effect of Capilal Punishment: Another View, 67 AM. ECON. Rev. 445 (1977); P. Passell \& J. Taylor, The Deterrent Effect of Capital Punishment: Another View (Feb. 1975) (unpublished manuscript). 
simple correlation between execution rates and homicide rates for death penalty jurisdictions. It became apparent that an adequate test of the deterrence hypothesis would have to incorporate as control variables additional factors associated with murder rates to properly identify the possible effect of the provision and level of use of the death penalty. ${ }^{18}$ To do otherwise is to examine murder in an etiological vacuum and run the risk of spurious results.

Thus, the second half of the 1970's through 1980 saw over a dozen multivariate deterrence studies. ${ }^{19}$ These studies were primarily of two forms: (1) cross-sectional examinations of state execution and murder rates for selected years, ${ }^{20}$ or (2) time-series analyses of the relationship between execution and murder rates at either the national or state level..$^{21}$

With but two exceptions, ${ }^{22}$ this new round of research found no support for the hypothesis that either the provision for capital punishment or the certainty of execution had a significant deterrent effect on murder. Moreover, some investigations attempted to replicate and verify Ehrlich's opposite findings. ${ }^{23}$ In general, the conclusion was that Ehrlich's confirmation of the deterrence hypothesis was simply a result of his applying a number of arbitrary, and in some cases dubious, assumptions and procedures in his analysis. ${ }^{24}$

18 Ehrlich made this clear in 1975 . Ehrlich, supra note 14.

19 These studies typically used multiple regression.

20 Bailey, supra note 10; Bailey, A Multivariate Cross-Sectional Analysis of the Deterrent Effect of the Death Penalty, 69 Soc. \& Soc. Research 183 (1980); Bailey, Imprisonment v. the Death Penalty as a Deterrent to Murder, 1 LAW \& HUM. BEHav. 239 (1977); Black \& Orsagh, New Evidence on the Efficacy of Sanctions as Deterrent to Homicide, 58 Soc. Sci. Q. 616 (1978); Ehrlich, Capital Punishment and Deterrence: Some Further Thoughts and Additional Evidence, 85 J. POL. ECON. 741 (1977); Forst, supra note 17; Kleck, Capilal Punishment, Gun Ownership, and Homicide, 84 AM. J. Soc. 882 (1979); Passell, The Deterrent Effect of the Death Penally: A Statistical Test, 28 STAN. L. REV. 61 (1975); Yunker, supra note 16.

21 Bailey, The Deterrent Effect of the Death Penalty: An Extended Time-Series Analysis, 10 Omega 235 (1979-80); Bailey, The Deterrent Effect of the Death Penalty for Murder in Ohio: A TimeSeries Analysis, 28 Clev. ST. L. REv. 51 (1979); Bailey, Deterrent Effect of the Death Penalty for Murder in Califomia, 52 S. CAL. L. REV. 743 (1979); Bailey, Deterrence and the Death Penalty for Murder in Oregon, 16 WillametTe L. Rev. 67 (1979); Bailey, An Analysis of the Deterrent Effect of the Death Penalty in North Carolina, 10 N.C. CENT. L.J. 29 (1978); Bailey, Deterrence and the Death Penally for Murder in Utah: A Time-Series Analysis, 5 J. ConTEMP. L. 1 (1978); Bowers \& Pierce, Deterrence or Brutalization: What Is the Effect of Executions?, 26 CRIME \& DELINQ. 453 (1980); Bowers \& Pierce, supra note 17; King, The Brutalization Effect: Execution Publicity and the Incidence of Homicide in South Carolina, 57 SOc. Forces 683 (1978); Kleck, supra note 20; Klein, Forst \& Filatov, supra note 17; Passell \& Taylor, supra note 17; W. Bowers \& G. Pierce, Deterrence, Brutalization or Nonsense? (1975) (unpublished manuscript).

22 Ehrlich, supra note 20; Yunker, supra note 16.

23 Ehrlich, supra note 14.

24 W. Bowers \& G. Pierce, supra note 21 (unpublished manuscript); Bowers \& Pierce, supra note 17, at 187-208; Brier \& Fienberg, supra note 17; Friedman, supra note 17; Klein, Forst \& Filatov, supra note 17; Passell \& Taylor, supra note 17. 
By the same token, however, a number of recent investigators are quick to point out that, despite these rather consistent findings, there is also no conclusive evidence that capital punishment is not, or cannot be, an effective deterrent to murder. ${ }^{25}$ Although the evidence to date does not, on balance, show a significant deterrent effect, even recent death penalty research suffers from some important methodological limitations that prevent us from concluding that capital punishment does not have a significant deterrent effect on murder. Until these remaining methodological issues are resolved, ${ }^{26}$ the deterrence question will remain an unresolved matter. ${ }^{27}$

\section{Problems of Aggregation and Measurement Bias}

In at least three important areas, both earlier and more recent deterrence studies suffer from bias because of the highly aggregated nature of the data being examined. ${ }^{28}$ First, with few exceptions, the only type of homicide subject to the death penalty is premeditated murder. ${ }^{29}$ However, not a single deterrence study has examined the relationship between the provision and/or level of use of capital punishment and first-degree murder rates. Rather, previous studies typically either (1) operationalized their dependent variable as homicide, and have made use of figures compiled by the United States Public Health Service, or (2) operationalized their dependent variable as murder and non-negligent manslaughter, and made use of data compiled by the Federal Bureau of Investigation (FBI). This practice is necessary because no public or private agency gathers nationwide data on premeditated murder. ${ }^{30}$

In using the more inclusive homicide and murder data in death

25 Brier \& Fienberg, supra note 17; Friedman, supra note 17; Klein, Forst \& Filatov, supra note 17.

26 Most of these issues involve potential problems of aggregation and measurement bias. See infra notes $28-44$ and accompanying text.

27 N. Kittrie \& E. Zenoff, Sanctions, Sentencing and Corrections 31 (1981); Brier \& Fienberg, supra note 17 at 187-88; Friedman, supra note 17, at 71-85; Klein, Forst \& Filatov, supra note 17 , at $357-59$.

28 N. KITTRIE \& E. ZENOFF, supra note 27, at 341.

29 Premeditated murder is variously referred to as first-degree murder, murder I, and aggravated murder.

30 In state statutes, first-degree murder typically includes both the elements of premeditation and malice aforethought. In general terms, premeditation refers to an intent to violate the law which is formulated prior to the activity, while malice aforethought refers to the simple presence of an intent to kill at the time of the act. The homicide category of murder and non-negligent manslaughter used by the FBI includes "all willful felonious homicides as distinguished from deaths caused by negligence," FEDERAL BUREAU OF INVESTIGATION, Crime in the United States-Uniform CRIME Report-1967, AT 61 (1968), AND THE PUBLIC HEALTH SERviCe defines homicide as "a death resulting from an injury purposely inflicted by another person," with intent to kill not required to classify a death as a homicide. U.S. Public Health Service, Homicide in the United States: 1950-1964 at 9 (1967). 
penalty studies, it is commonly assumed that the ratio of first degree murders to homicides or murder and non-negligent manslaughters is constant, so that the latter types of figures provide a reasonably good indicator of capital offenses. As Sellin ${ }^{31}$ and Bedau ${ }^{32}$ have pointed out, however, this is only an assumption. There is no hard evidence to justify this practice. Accordingly, until more refined murder data are examined, the extent of bias present in previous studies will remain an important but unresolved question. ${ }^{33}$

A second potential area of bias in death penalty studies stems from the type of political/geographic bodies used as the units of analysis or measurement. For instance, in a number of recent studies researchers have examined the correspondence between aggregate execution rates and homicide or murder rates on a national level for various time periods, most commonly from the 1930's through the late 1960's. These studies are seriously flawed because no attention has been paid to (1) the tremendous state-to-state variation in offense rates during these years, (2) the considerable variation in execution rates from state to state in retentionist jurisdictions, and the fact that execution rates, by definition, were zero in abolitionist states, and (3) the tremendous variation from state to state in the sociodemographic and other control variables introduced into the analysis. These studies have simply treated this important variation as if it does not exist. Moreover, and with particular reference to Ehrlich's study, ${ }^{34}$ measurement error problems for an execution rate variable are very serious when homicide and execution data are aggregated at the national level. In such a situation, even slight measurement error may contribute to a spurious negative relationship between execution and murder rates. ${ }^{35}$

Because of these problems, it appears that states are a preferable unit of analysis in time-series as well as cross-sectional designs. Even aggregation at the state level, however, may result in substantial error and possible bias. ${ }^{36}$ For example, it has long been observed that murder rates are much higher in some areas of a state than in others, ${ }^{37}$ but com-

31 T. Sellin, supra note 3 , at 135 .

$32 \mathrm{H}$. Bedau, supra note 2, at 36 .

33 N. KITTRIE \& E. Zenoff, supra note 27; Brier \& Feinberg, supra note 17; Friedman, supra note 17; Klein, Forst \& Filatov, supra note 17.

34 Ehrlich, supra note 14.

35 Bowers \& Pierce, supra note 17; Bowers \& Pierce, Deterrence, Brutalization or Nonsense?, supra note 21; Brier \& Fienberg, supra note 17; Friedman, supra note 17; Klein, Forst \& Filatov, supra note 17; Passell \& Taylor, supra note 17.

36 Greenberg, Deterrence Research and Social Poligy, in Modeling the Criminal Justice System (S. Nagel ed. 1977); Logan, Amest Rates and Deterrence, 56 Soc. ScI. Q. 376 (1975); Orsagh, Empirical Criminology: Interpreting Results Derived from Aggregate Data, 16 J. RESEARCH CRIME \& Deline. 294 (1979).

37 For example, there are often such differences between urban and rural areas of a state. 
puting murder rates at the state level disguises this important variation. Similarly, the ratio of executions to murders varies considerably between areas within many retentionist states, ${ }^{38}$ but aggregate execution rates ignore this variation. Finally, the very same difficulties are present when sociodemographic and other control variables are measured at the state level, and this is particularly a problem when very heterogeneous jurisdictions are considered.

The possibility of bias in using state-wide data is confirmed by a recent study by Greenberg, Kessler, and Logan, ${ }^{39}$ which found that the relationship between arrest rates and rates for major felonies (including murder) varies considerably depending upon whether states or cities are used as the unit of analysis. The study found considerable aggregation bias in the state level analysis. ${ }^{40}$ It remains to be seen, however, whether this pattern holds when cities are used as the unit of analysis in death penalty studies. Such an analysis is the next logical step in death penalty research. ${ }^{41}$

A third source of potential aggregation and measurement bias comes from the typical practice of using one-year time intervals (normally the calendar year) in computing murder and execution rates and examining the correspondence between them. This practice is necessary because homicide and murder data available for death penalty studies are generally only reported on a calendar year basis, rather than a monthly, weekly or daily basis. Similarly, until the publication of the complete Teeters-Zibulka Inventory of executions under state authority, ${ }^{42}$ only annual execution figures were available from periodic publications released by the Federal Bureau of Prisons.

The primary problems that result from examining yearly execution and offense data are threefold. First, the deterrent effect of capital punishment may be short-term and have its major impact on the rate of murder within the month or two after execution. ${ }^{43}$ This remains an open question, but if this is the case, then examining yearly murder data will have the effect of disguising or diluting the impact of executions.

38 W. BOWERS, EXECUTIONS IN AMERICA 202-401 (1974).

39 Greenberg, Kessler \& Logan, Aggregation Bias in Deterrence Research: An Empirical Analysis, 18 J. Research Crime \& DelinQ. 128 (1981).

40 For the same reasons, a growing number of investigators have moved from using states to using either cities or counties as their units of analysis in examining the deterrent effect of arrest and imprisonment practices. Brown, Arest Rates and Crime Rates: When Does a Tipping Effect Occur?', 57 SOC. FORCES 671 (1978); Greenberg, Kessler \& Logan, supra note 39; Greenberg, Kessler \& Logan, A Panel Model of Crime Rates and Arrest Rales, 44 AM. Soc. REv. 843 (1979); Tittle \& Rowe, Certainty of Arrests and Crime Rates: A Further Test of the Deterrence Hypothesis, 52 SOC. FORCES 455 (1974).

41 N. Kittrie \& E. Zenoff, supra note 27, at 341.

42 W. BOWERS, supra note 38, at 200.

43 Bowers \& Pierce, Deterrence or Brutalization, supra note 21. 
Second, when executions and murders are considered on a calendar year basis, it becomes very difficult to properly establish the temporal sequence between these two factors. To illustrate, it would make little sense to expect an execution carried out during December of year $t$ to be much evidenced in the annual twelve-month murder rate for year $t$. This is obvious because eleven months worth of murders during year $t$ occurred before the execution. Rather, the deterrent effect of such an execution could only be felt during December of year $t$ and possibly, for the reasons noted above, during the first few months of year $t+1$.

Some investigators have tried to deal with the possible delayed deterrent effect of executions by building in a one-year time lag between executions (year $\mathrm{t}$ ) and murders (year $\mathrm{t}+1$ ). However, whether this procedure is employed in a time-series or cross-sectional design, the difficulty is the same: there is no assurance that the actual time lag between executions and the murder rate is the same. To illustrate, for both State $A$ and State $B$, murder rates for year $t+1$ are being examined, but the last execution during year $t$ in State $A$ may have been in January, whereas the last execution during year $t$ in State $B$ may have been in December. Here, the actual time lags being considered for the two hypothetical states differ by about one year. This is obviously an extreme example posing the maximum possible difference. The fact remains, however, that states have been far from uniform in their monthly execution practices, ${ }^{44}$ and the possible bias resulting from previous studies which rely upon yearly execution and murder data cannot be ignored.

\section{The Present Investigation}

In this investigation we attempt to overcome each of the above aggregation and measurement error problems by providing a monthly time-series analysis of executions and first-degree murders in the city of Chicago, Illinois for the period 1915-1921.45 Although these first-degree murder and execution data are now somewhat dated, their importance in providing a clearer understanding of the possible deterrent effect of executions on capital homicides is not diminished. Moreover, if deterrence is a communication effect as Gibbs ${ }^{46}$ and others contend, then Chicago provides an ideal research setting since there is close geographic proximity between the place where first-degree murders are committed

\footnotetext{
44 Teeters \& Zibulka, Executions Under State Authority: 1864-1967, in W. BOWERs, ExecuTIONS IN AMERICA 200, 202 (1974).

45 This analysis is made possible by the availability of unpublished execution figures for Cook County Prison compiled by Hans Mattrick, its former assistant warden, which have been provided to me by Thorsten Sellin, and monthly first-degree murder data covering the seven-year period reported by the Chicago Police Department in its annual reports.

46 J. Gibbs, Crime, Punishment and DeterRence (1975).
} 
and the place where the convicted murderers are executed. In many states, executions are performed in facilities that are far removed from major population centers where the majority of murders occur. In contrast, in Chicago every convicted murderer executed during the period under study was put to death in the Cook County Prison located in the city. Accordingly, Chicago residents, including would-be killers, should have had a more direct awareness of murder and its possible consequence (the certainty of execution) than residents of larger jurisdictions such as states or the nation.

\section{A. METHODS AND PROCEDURES}

\section{Method of Analysis}

In examining the deterrent effect of executions on first-degree murders in Chicago, we use the following general model: ${ }^{47}$

FM = (EXEC, ARR, PRIS, DEN, PUB, SEA).

This model represents the hypothesis that the monthly number of firstdegree murders (FM) is a function of the number of executions for firstdegree murder (EXEC); the certainty of arrest for murder I (ARR); the certainty of imprisonment for murder I (PRIS); population density (DEN); the percent of the city's budget expended on public assistance for the homeless and other needy adults and children (PUB); and the season of the year (SEA). Previous research has found sociodemographic and seasonal variables included on the right-hand side of the equation, or similar ones, to be associated with murder rates, and they are consid-

47 Although we pose, theoretically, deterrence as the causal connection between executions and murder, Gibbs, supra note 10, claims that the normative validation effect of executions also has to be considered. See J. GiBBS, supra note 46. Normative validation "occurs when an individual's condemnation of some type of criminal act is maintained as a consequence of prescribed legal punishments or their application to other individuals." Gibbs, supra note 10, at 40 . In the case of capital punishment, executions could affect, theoretically, the rate of murder either through deterrence or normative validation. That is, both arguments predict an inverse relationship between the level of executions and the level of murder. W. BERNS, For Capital Punishment: Crime and the Morality of the Death Penalty 145 (1979); E. VAN den HaAg, Punishing Criminals: Concerning a Very Old and Painful Question 70 (1975); Lehtinen, The Value of Life: An Argument for the Death Penally, 23 CRIME \& Deling. 237 (1977); van den Haag, On Deterrence and the Death Penally, 60 J. CRIM. L., Criminology \& Police Sai. 141 (1969). According to Gibbs, supra note 10, and Brier \& Fienberg, supra note 17, however, there apparently is no feasible way of separating the possible deterrent from normative validation effects of capital punishment.

Whereas Gibbs, supra notes $10 \& 46$, is adamant in drawing a distinction between the deterrent and normative validation effects of sanctions, most researchers have adopted a more flexible conceptualization that incorporates both deterrence and normative validation under the phrase "general deterrence." C. Tittle, Sanctions and Social Deviance: The QUESTION OF DETERRENCE (1980). Because this is the more common usage in the death penalty literature, and for reasons of brevity in our discussion, we shall use the term deterrence to also incorporate the possible normative validation effect of executions on murder. 
ered here as control factors to avoid spurious results for the execution variable. In addition, and for the same reasons, certainty of arrest and imprisonment for murder are also included in the model as control factors. Some previous investigations have found certainty of arrest and imprisonment to be negatively, and significantly, associated with homicide rates.

At first glance, it appears that our model ignores some possibly important sociodemographic factors associated with murder. For example, some previous investigations found a very significant relationship between murder rates and such factors as percent of population that is nonwhite, percent of male population fifteen to thirty-four years of age, and percent of population foreign born. These factors were considered for possible inclusion in our model, but they were rejected because of the high degree of multicollinearity they would have introduced into the analysis. The association among these factors would have resulted in very unreliable parameter estimates coming from the regression analysis. ${ }^{48}$

Although a theoretical argument can be made for including each of these three sociodemographic factors in the analysis, their high degree of correspondence precludes including even two of them in the model. In addition, if we decide to include only one of these variables in the analysis, the obvious questions become which one, and whether the resulting findings should be interpreted as indicating the effects of race, age/sex, or foreign born population on murders.

Rather than make such an arbitrary decision, all three factors are excluded from the model, but their possible effect on murder is not totally ignored. The population density factor included in the model is very highly correlated with the nonwhite population $(r=.950)$, male population fifteen to thirty-four years of age $(r=-.969)$ and the foreign born population $(r=-.999)$ variables. Accordingly, population density can be viewed as a proxy variable for changes in Chicago in these three sociodemographic areas, besides having its own theoretical justification for consideration.

To examine the effect of executions on first-degree murders, a series of multiple regression analyses were performed where various execution measures and time-lag structures were considered. In addition, more general monthly homicide figures, similar to those included in the FBI's category of murder and non-negligent manslaughter, were considered in the analysis for comparative purposes and to determine the impact of

48 For nonwhite population and male population 15 to 34 years of age, $r=-.991$; for nonwhite population and percent of population foreign born, $r=-.947$; for male population 15 to 34 years of age and percent of population foreign born, $r=.946$. 


\section{The Dependent Variables}

For each year, 1915 through 1921, monthly $(n=84)$ first-degree murder figures were taken from the annual statistical reports of the Chicago Police Department. ${ }^{50}$ Under Illinois law during this period, firstdegree (premeditated) murder was the only type of homicide eligible for capital punishment. The type of indictment reached by the Cook County Grand Jury determined how killings were classified in the police reports.

Figures for total criminal homicides (including first-degree murders) were also extracted from the annual Chicago police reports in order to examine the effect of executions on all types of criminal homicides. ${ }^{51}$ Although most of these homicides would not lead to the death penalty, the moralizing, normative validation, and educative effect of executions may also reduce noncapital homicides. ${ }^{52}$ Indeed, the major function of the threat and application of criminal law may lie in its moral and educative role in society. ${ }^{53}$

49 To test for possible problems of multicollinearity, we examined our basic model with each execution variable using the variance decomposition method developed in A. BELSLEY, E. KUH \& R. Welsch, Regression Diagnostics: IDENTIFying INfluential Data and SOURCES OF COLlinearity (1980). This analysis did not indicate any significant collinearity problems. Interestingly, population density is the factor most strongly associated with the number of executions $(r=.448)$ and the execution dummy variable $\left(r^{\circ}=.453\right)$. However, this does not pose a problem in the analysis either by itself or in linear combination with the other predictor variables. When the number of executions is regressed against the other five right-hand variables included in the murder I analysis, a significant $(p<.01) R^{2}$ value of .217 results. This compares to an $R^{2}$ of $.223(p<.01)$ when the dummy execution variable is considered. Similarly, when the number of executions and the dummy execution variable are regressed against the five right-hand factors considered in the homicide analysis, significant $(p<.01) R^{2}$ values of .216 and .220 , respectively, result. These $R^{2}$ values indicate that the majority of the variation in each execution measure is not accounted for by any or all of the other predictor variables. Accordingly, there is no indication that the findings to be presented for the execution variables in Tables 2-10 suffer from problems of multicollinearity. In addition, the analysis shows that the other right-hand factors do not suffer from serious collinearity problems.

50 Only during this seven-year period do the annual reports disaggregate homicide figures by month and type of killing.

51 With a few slight exceptions, the types of killings included in the criminal homicide data for Chicago are comparable to the types of killings included in the FBI offense category of murder and non-negligent manslaughter. See FBI, CRIME IN THE UNITED STATES, supra note 30, at 61. Excluded from the Chicago homicide data are a few deaths resulting from illegal abortions, infant neglect, criminal carelessness with a wagon or automobile, and deaths resulting from illegally produced alcohol. In addition, 38 killings resulting from the Chicago race riot of 1919 are excluded from the analysis.

52 E. VAN DEN HAAG, PUNISHING CRIMINAls, supra note 21, at 212-13, 225; Lehtinen, The Value of Life: An Argument for the Death Penalty, 23 CRIME \& Delline. 237, 240-42 (1977); van den Haag, On Deterrence and the Death Penally, supra note 47, at 143.

53 E. Durkheim, The Division of Labor in Society (1949); J. Gorecki, A Theory 


\section{Execution Variables}

In examining monthly first-degree murders and total criminal homicides, two execution measures are utilized: (1) the actual number of monthly executions, and (2) a dummy execution variable, where execution months are assigned a weight of one (1.0) and non-execution months a weight of zero (0.0)..$^{54}$ If the public, including would-be killers, is sensitive to the actual volume of executions via the deterrence thesis, then the former measure should prove superior to the latter, which simply reflects the presence or absence of an execution during a month. Both types of measures have been used by previous investigators and are considered here for comparative purposes. ${ }^{55}$

\section{Control Variables}

The two sociodemographic control variables considered in the analysis are population density and percent of the city budget expended on care (food and shelter) for the homeless and other needy adults and children. ${ }^{56}$ These factors are included in the analysis to control for changes in the nature of the Chicago population and socioeconomic conditions during the seven-year period. In addition, the population density variable has the effect of controlling for changes in population size since the boundaries of Chicago did not change from 1915 through 1921.57

Season of the year is also included as a control variable. Investigations have long found that murder rates are generally higher during the summer months and in December. The typical explanation for this pattern is that during the summer months and in December (a holiday month) there is a greater level of social intercourse and alcohol con-

of Criminal Justice (1979); H. Packer, The Limits of the Criminal Sanction (1968); F. Tannenbaum, Crime and the Community (1938); P. Tappan, Crime, Justice and Correction (1960); Andenaes, General Prevention Revisited: Research and Policy Implications, 66 J. CRIM. L. \& CRImINology 338 (1975); Andenaes, The General Preventive Effects of Punishment, 114 U. PA. L. Rev. 949 (1966); Andenaes, General Prevention: Illusion or Reality?, 43 J. CRIM. L. Criminology \& Police Sci. 176 (1952).

54 Following the type of procedure used by King, supra note 22, executions during the first half of a month were recorded as occurring during the month (month $t$ ) and those during the second half of a month were recorded as occurring during the next month (month $t+1$ ). Short of weekly or daily data for killings, this is as close as the correspondence between executions and murders or homicides can be approximated.

55 From 1915 through 1921 there were 26 executions for first-degree murder in Chicago; an average of about one execution every 3.2 months during the 84-month period.

56 The data for these variables come from the Department of Commerce, Bureau of Census publications and W. Skogan, Chicago Since 1840: A Time-Series Data Handbook (1976). Monthly figures were linearly interpolated.

57 Accordingly, it is also not necessary to compute rates for the murder and homicide variables since inclusion of the population density factor in the analysis controls for changes in population from 1915 through 1921. 
sumption, two factors that contribute to murder. ${ }^{58}$ To control for this possible effect, a seasonal dummy variable was constructed with the summer months ${ }^{59}$ and December assigned a weight of one (1.0) and the remaining months a weight of zero $(0.0)$.

Finally, certainty of arrest and imprisonment for murder are considered in the analysis as control factors to better isolate the hypothesized deterrent effect of executions. A handful of cross-sectional studies of cities and states have found evidence that certainty of arrest and imprisonment do have at least some degree of deterrent (and/or incapacitative) effect on homicides. ${ }^{60}$ To control for this possibility for Chicago during the period considered, annual certainty of imprisonment values for first-degree murder were computed by the following formula: certainty $=[$ (No. of imprisonments for murder I / No. of arrests for murder $I \times 100]$. Similarly, when total criminal homicides are considered as the dependent variable in the analysis, a broader measure of certainty of imprisonment is utilized: certainty $=[$ (No. of imprisonments for homicide $/$ No. of arrests for homicide) $\times 100$ ]. In computing these measures, which result in a percent imprisonment figure for each year for each type of killing, the few cases where the accused was killed, committed suicide before trial, or was sent to a mental hospital rather than a penal institution, as well as cases that were pending at the end of the year without disposition, were excluded from consideration in computing certainty values. ${ }^{61}$

A similar procedure was also followed in computing annual estimates of the certainty of arrest for first-degree murder: certainty = [(No. of arrests for murder I / No. murder I killings) $\times 100]$; and the certainty of arrest for homicide: certainty $=[$ (No. of arrests for homicide / No. of homicides) $\times 100$ ]. Alternative arrest "clearance rate" figures for either type of killings are not available from Chicago Police Department records.

58 E. Sutherland, Principles of Criminology 82 (1947).

59 The summer months are June, July, and August.

60 Bean \& Cushing, Criminal Homicide, Punishment and Deterrence: Methodological and Substantive Reconsiderations, 52 Soc. ScI. Q. 277 (1971); Ehrlich, Participation in Illegitimate Activities: $A$ Theoretical and Empirical Investigation, 81 J. POL. ECON. 521 (1973); Gibbs, supra note 11; Gray \& Martin, Punishment and Deterrence: Another Analysis of Gibbs' Data, 50 Soc. Sar. Q. 389 (1969); Logan, supra note 36; Logan, General Deterrent Effects of Imprisonment, 51 SOC. FORCES 64 (1972); Tittle \& Rowe, supra note 40.

61 Because monthly arrest and imprisonment data are not available for Chicago for either type of killing, certainty values had to be computed on a yearly basis and used as estimates for each month falling within the year. We do not see using yearly estimates of certainty as posing a serious theoretical problem, however, due to the normal delay for those convicted (on occasion, as much as a year or more during the period examined) between arrest and imprisonment. 


\section{TABLE 1}

Zero-Order Correlations and Descriptive Statistics for Variables Included in the Model: Chicago, 1915-1921

\begin{tabular}{|c|c|c|c|c|c|c|c|c|c|c|c|c|}
\hline & Variable & (1) & (2) & (3) & (4) & (5) & (6) & (7) & (8) & (9) & (10) & (11) \\
\hline (1) & First Degree Murder & 1.00 & $.577 \mathrm{~b}$ & $.432 \mathrm{~b}$ & .044 & .072 & $-.400 \mathrm{~b}$ & -.150 & -.031 & $-.241 \mathrm{a}$ & .158 & .186 \\
\hline (2) & Criminal Homicide & & 1.00 & -.193 & .210 & .109 & -.179 & $-.383 b$ & -.140 & -.145 & -.182 & -.108 \\
\hline (3) & Population Density & & & 1.00 & $-.376 b$ & .049 & $-.499 b$ & $.226 \mathrm{a}$ & .020 & $-.426 \mathrm{~b}$ & $.448 \mathrm{~b}$ & $.453 \mathrm{~b}$ \\
\hline (4) & Public Assistance & & & & 1.00 & .000 & -.148 & $-.442 \mathrm{~b}$ & -.056 & .170 & -.195 & -.162 \\
\hline (5) & Season & & & & & 1.00 & .000 & .000 & .000 & .000 & .000 & -.020 \\
\hline (6) & Prison for Murder & & & & & & 1.00 & $.466 \mathrm{~b}$ & $-.312 b$ & $.349 \mathrm{~b}$ & -.131 & -.161 \\
\hline (7) & Prison for Homicide & & & & & & & 1.00 & .026 & -.095 & .207 & .156 \\
\hline (8) & Arrest for Murder & & & & & & & & 1.00 & $.615 \mathrm{~b}$ & .023 & .057 \\
\hline (9) & Arrest for Homicide & & & & & & & & & 1.00 & -.141 & -.104 \\
\hline (10) & No. of Executions & & & & & & & & & & 1.00 & $.880 \mathrm{~b}$ \\
\hline (11) & Executions Dummy & & & & & & & & & & & 1.00 \\
\hline & Mean & 9.02 & 18.99 & $14,138.0$ & 1.81 & .33 & 66.71 & 59.71 & 80.85 & 80.86 & .32 & .23 \\
\hline & S.D. & 3.63 & 5.23 & 745.1 & .17 & .47 & 9.37 & 8.53 & 10.85 & 9.72 & .68 & .42 \\
\hline & Min. & 1.00 & 6.00 & $13,235.0$ & 1.60 & 0.00 & 51.00 & 41.00 & 66.00 & 65.00 & 0.00 & 0.00 \\
\hline & Max. & 19.00 & 36.00 & $15,648.0$ & 2.11 & 1.00 & 84.00 & 70.00 & 100.00 & 97.00 & 3.00 & 1.00 \\
\hline
\end{tabular}

$a=p<.05$

$\mathrm{b}=\mathrm{p}<.01$ 


\section{B. FINDINGS}

Table 1 presents a descriptive profile of the factors included in our model as well as the zero-order correlations among the variables. To reiterate, our model predicts a significant negative relationship between executions and the number of first-degree murders and total criminal homicides. Table 2 reports the results of an ordinary least squares (OLS) analysis where the number of monthly first-degree murders is regressed against the number of executions, the execution dummy $(0 / 1)$ variable, and the control factors.

\section{TABLE 2}

OLS: Number of MONTHLy First Degree Murders Regressed Against Number of Executions, an EXecution Dummy VariaBle, and Other Selected Factors; Chicago, 1915-1921*

\begin{tabular}{|l|r|c|r|r|}
\hline \hline \multicolumn{2}{c}{ No. Executions } & \multicolumn{2}{c|}{ Execution Dummy } \\
\hline Independent Variable & \multicolumn{1}{c|}{$\mathrm{B}$} & \multicolumn{1}{c|}{$\mathrm{t} / \mathrm{F}$} & \multicolumn{1}{c|}{$\mathrm{B}$} & \multicolumn{1}{c|}{$\mathrm{t} / \mathrm{F}$} \\
\hline \hline Population Density & .002 & $2.547 \mathrm{a}$ & .002 & $2.440 \mathrm{a}$ \\
Public Assistance & 3.202 & .220 & 3.169 & 1.222 \\
Season & .410 & .546 & .417 & .580 \\
Cert. of Arrest & -.033 & -.919 & -.034 & -.935 \\
Cert. of Prison & -.085 & -1.591 & -.086 & -.109 \\
Executions & -.059 & -.101 & .114 & .119 \\
Constant & -14.955 & -.874 & -13.843 & -.803 \\
$\mathrm{R}^{2}$ & .264 & $4.62 \mathrm{~b}$ & .265 & $4.62 \mathrm{~b}$ \\
D.W. & 1.799 & & 1.804 & \\
\hline \hline
\end{tabular}

* For the unstandardized regression coefficients (B), $t$ values are reported; for the multiple $R^{2}$ values, $F$ values are reported.

$$
\begin{aligned}
& \mathrm{a}=\mathrm{p}<.05 \\
& \mathrm{~b}=\mathrm{p}<.01
\end{aligned}
$$

Contrary to the deterrence hypothesis, this analysis provides no evidence that executions are an effective deterrent to first-degree murder. When the actual number of monthly executions and murders are considered, these two factors are negatively associated, ${ }^{62}$ as the deterrence hypothesis predicts. The negative relationship is slight, however, and is not statistically significant. Moreover, when the execution dummy variable is considered, executions and murders are positively associated. ${ }^{63}$ This relationship is also slight, however, and is not statistically significant.

$62 \mathrm{~B}=-.059 ; \mathrm{t}=-.101$.

$63 \mathrm{~B}=.114 ; \mathrm{t}=.119$. 
Additionally, Table 2 provides no indication that the certainty of arrest or imprisonment are effective deterrents to first-degree murder. When both execution measures are considered, the arrest and imprisonment coefficients are in the expected negative direction, but they fall short of reaching statistical significance at the .05 level. In contrast, population density is a significant predictor of murders in each analysis.

Also of note, the Durbin-Watson (D.W.) statistics allow us to accept the null hypothesis of no first-order serial correlation when both the number of executions and the execution dummy variable are examined. In addition, the same pattern holds when error structures for lag periods as far back as t-12 months are considered. Accordingly, it would appear that the OLS results reported in Table 2 do not suffer from autocorrelation bias.

\section{TABLE 3}

OLS: Number of MONTHLy Homicides Regressed Against Number of EXecutions, an EXecution Dummy Variable, and Other Selected Factors; Chicago, 1915-1921*

\begin{tabular}{|l|r|c|c|c|}
\hline \hline \multicolumn{2}{c}{ No. Executions } & \multicolumn{2}{c|}{ Execution Dummy } \\
\hline \hline Independent Variables & \multicolumn{1}{c|}{$\mathrm{B}$} & $\mathrm{t} / \mathrm{F}$ & $\mathrm{B}$ & $\mathrm{t} / \mathrm{F}$ \\
\hline Population Density & -.001 & -1.640 & -.002 & -1.932 \\
Public Assistance & .507 & .139 & .437 & .120 \\
Season & 1.309 & 1.192 & 1.340 & 1.217 \\
Cert. of Arrest & -.149 & $-2.521 \mathrm{a}$ & -.153 & $-2.572 \mathrm{a}$ \\
Cert. of Prison & -.210 & $-3.065 \mathrm{~b}$ & -.216 & $-3.155 \mathrm{~b}$ \\
Executions & -.406 & -.470 & .442 & .753 \\
Constant & 63.236 & $3.371 \mathrm{~b}$ & 67.897 & $3.578 \mathrm{~b}$ \\
R2 & .238 & $4.01 \mathrm{~b}$ & .237 & $3.99 \mathrm{~b}$ \\
D. W. & 1.582 & & 1.578 & \\
\hline \hline
\end{tabular}

* For the unstandardized regression coefficients (B), $t$ values are reported; for the mulitple $R^{2}$ values, $F$ values are reported.

$\mathrm{a}=\mathrm{p}<.05$
$\mathrm{~b}=\mathrm{p}<.01$

Table 3 reports the analysis where the monthly number of criminal homicides is treated as the dependent variable. The findings for the execution variables parallel the previous analysis for murder. The number of executions is negatively associated with homicides, and the execution dummy variable is positively associated with homicides. In neither case, however, is the association between these two factors statistically significant. 
Unlike with murder I, both the certainty of arrest and the certainty of imprisonment are statistically significant predictors of homicides. Regardless of the execution measure used, the greater the certainty of arrest, the lower the number of homicides. Similarly, the greater the certainty of imprisonment, the lower the number of homicides. These findings are consistent with what deterrence theory predicts and with the findings of some previous studies. ${ }^{64}$ The significant $t$ values for the arrest and imprisonment variables, however, may be to some degree suspect. For both analyses, the Durbin-Watson statistic indicates the presence of a positive first-order serial correlation that has the effect of producing downwardly biased standard errors and, accordingly, upwardly biased $t$ ratios. This could account for the significant $t$ values for the arrest and imprisonment variables.

Although our primary concern is with the deterrent effect of executions and not certainty of arrest and imprisonment, the homicide equations reported in Table 3 were re-estimated using the Cochrane-Orcutt (CORG) iterative procedure for first-order autocorrelation. ${ }^{65}$ Results are reported in Table 4.

\section{TABLE 4}

GORG: Number of MONTHLy Homicides Regressed Against Number of EXecutions, aN EXecution DumMy VARIable, AND Other Selected Factors; Ghicago, 1915-1921*

\begin{tabular}{|l|r|c|c|c|}
\hline \hline & \multicolumn{2}{c|}{ No. Executions } & \multicolumn{2}{c|}{ Execution Dummy } \\
\hline Independent Variable & \multicolumn{1}{c}{$\mathrm{B}$} & $\mathrm{t} / \mathrm{F}$ & $\mathrm{B}$ & $\mathrm{t} / \mathrm{F}$ \\
\hline Population Density & -.001 & -1.336 & -.002 & -1.471 \\
Public Assistance & .901 & .204 & .830 & .188 \\
Season & 1.888 & $1.683 \mathrm{a}$ & 1.912 & $1.703 \mathrm{a}$ \\
Cert. of Arrest & -.152 & $-2.070 \mathrm{a}$ & -.155 & $-2.104 \mathrm{a}$ \\
Cert. of Prison & -.210 & $-2.544 \mathrm{~b}$ & -.215 & $-2.611 \mathrm{~b}$ \\
Executions & -.243 & -.311 & .215 & .170 \\
Constant & 62.074 & $2.726 \mathrm{~b}$ & 64.896 & $2.832 \mathrm{~b}$ \\
R2 & .275 & $4.81 \mathrm{~b}$ & .275 & $4.79 \mathrm{~b}$ \\
D. W. & 1.970 & & 1.964 & \\
\hline \hline
\end{tabular}

* For the unstandardized regression coefficients (B), $t$ values are reported; for the multiple $R^{2}$ values, $F$ values are reported.

$\mathrm{a}=\mathrm{p}<.05$

$\mathrm{b}=\mathrm{p}<.01$

64 See, e.g., Bailey, Martin \& Gray, Crime \& Deterrence: A Correlation Analysis, 11 J. RESEARCH CRIME \& DelinQ. 124 (1974); Gray \& Martin, Punishment and Deterrence: Another Analysis of Gibbs' Dala, 50 Soc. ScI. Q. 289 (1969); Logan, General Deterrent Effects of Imprisonment, 51 SOC. FORCES 64 (1972).

65 To test and correct for serial correlation problems, the SAS (Statistical Analysis Sys- 
This reanalysis does not alter the basic findings for the sanction variables. There continues to be only a chance relationship between executions and homicides, and a statistically significant negative relationship between the certainty of arrest and imprisonment and homicides. Unlike the findings in Table 3 , in Table 4 season becomes a significant predictor of homicides, with a larger number of killings in December and during the summer months. Although the results vary somewhat for the season variable when possible higher-order autocorrelation processes are explored, ${ }^{66}$ the results for the sanction variables are not altered. There remains only a chance relationship between executions and homicides, and a significant negative relationship between arrest and imprisonment and homicides.

\section{THE EFFECT OF LAGGED EXECUTIONS}

Up to this point we have considered solely the relationship between executions and first-degree murders and homicides within the same month, and the evidence is inconsistent with the deterrence hypothesis. It is possible, however, that the deterrent effect of executions is not felt primarily during the month of execution, but during the next month, or the next few months. Unfortunately, proponents of deterrence theory and capital punishment are not explicit about the proper time lag to consider in an investigation such as ours. However, if the effect of executions is delayed, our analysis to this point does not provide an adequate test of the deterrence hypothesis.

To explore this question, we next regress the number of monthly (month t) first-degree murders and total criminal homicides against the control variables, the number of executions and the execution dummy variable for months $t$ through $t-12$. This analysis takes into consideration the possibility that the deterrent effect of capital punishment may not be experienced until as much as twelve months after an execution. The results of this analysis for first-degree murder are presented in Table 5 .

tem) autoregression (AUTO REG) routine is utilized. This procedure first estimates a model using ordinary least squares and then computes autocorrelations up to the lag period requested using the residuals from the OLS regression. The Yule-Walker equations are solved to obtain estimates of the autoregressive parameters. Here we explore possible autoregressive processes up to lag period $t-12$ months. Where significant $(p<.05)$ autocorrelations result for a lag period, the original data are appropriately transformed and parameters are re-estimated using OLS regression.

66 Months t-2 through $\mathrm{t}-12$. 


\section{TABLE 5}

OlS: Number of Monthly First Degree Murders Regressed Against Lagged Number of EXecutions, a LagGed EXecuTION Dummy Variable, and Other Selected Factors; Ghicago, 1915-1921*

\begin{tabular}{|l|r|r|r|r|}
\hline \hline & \multicolumn{2}{c|}{ No. Executions } & \multicolumn{1}{c|}{ Execution Dummy } \\
\hline \hline Independent Variables & $\mathrm{B}$ & $\mathrm{t} / \mathrm{F}$ & \multicolumn{1}{c|}{$\mathrm{B}$} & $\mathrm{t} / \mathrm{F}$ \\
\hline Population Density & -.001 & -.443 & -.000 & -.150 \\
Public Assistance & 2.458 & .938 & 2.445 & .893 \\
Season & .335 & .417 & .345 & .431 \\
Cert. of Arrest & -.026 & -.663 & -.037 & -.978 \\
Cert. of Prison & -.112 & $-1.805 \mathrm{a}$ & -.106 & $-1.861 \mathrm{a}$ \\
Executions & & & & \\
Month t & .468 & .686 & 1.089 & 1.012 \\
Month t-1 & .882 & 1.168 & 2.713 & $2.373 \mathrm{a}$ \\
Month t-2 & -.527 & -.696 & .836 & .712 \\
Month t-3 & -.452 & -.574 & -.480 & -.405 \\
Month t-4 & .750 & .885 & .317 & .257 \\
Month t-5 & .503 & .586 & .821 & .648 \\
Month t-6 & -.673 & -.748 & -1.076 & -.830 \\
Month t-7 & 1.302 & 1.466 & .674 & .512 \\
Month t-8 & 1.086 & 1.183 & .831 & .663 \\
Month t-9 & .673 & .780 & .620 & .483 \\
Month t-10 & 1.896 & $2.162 \mathrm{a}$ & 1.148 & .927 \\
Month t-11 & 1.206 & 1.350 & -.224 & -.172 \\
Month t-12 & .620 & .716 & .445 & .352 \\
Constant & 26.190 & .756 & 17.370 & .516 \\
R2 & .388 & $2.29 \mathrm{~b}$ & .379 & $2.21 \mathrm{~b}$ \\
D.W. & 1.914 & & 1.893 & \\
\hline \hline
\end{tabular}

* For the unstandardized regression coefficients (B), $t$ values are reported; for the multiple $R^{2}$ values, $F$ values are reported.

$$
\begin{aligned}
& \mathrm{a}=\mathrm{p}<.05 \\
& \mathrm{~b}=\mathrm{p}<.01
\end{aligned}
$$

Table 5 provides no consistent support for the deterrence hypothesis for capital punishment. When the number of executions is considered, a minority (3/13) of the execution coefficients are negative and none are statistically significant. In contrast, executions and murders are positively associated for most lag periods (10), and the positive execution coefficient is significant for lag period $t-10$ months. ${ }^{67}$

A similar pattern holds when the execution dummy variable is examined. Again, only a minority (3/13) of the execution coefficients are 
TABLE 6

GORC: Number of Monthly First Degree Murders ReGRessed Against Lagged Number of EXecutions, a LagGed Execution Dummy Variable, and Other Selected Factors; CHICAGO, 1915-1921*

\begin{tabular}{|l|r|r|r|r|}
\hline \hline \multicolumn{2}{|c|}{ No. Executions } & \multicolumn{2}{c|}{ Execution } & Dummy \\
\hline \hline Independent Variable & \multicolumn{1}{c|}{$\mathrm{B}$} & $\mathrm{t} / \mathrm{F}$ & \multicolumn{1}{c|}{$\mathrm{B}$} & $\mathrm{t} / \mathrm{F}$ \\
\hline Population Density & -.002 & -1.180 & -.001 & -.783 \\
Public Assistance & .820 & .399 & .774 & .331 \\
Season & .501 & .638 & .596 & .755 \\
Gert. of Arrest & -.033 & -1.113 & -.049 & -1.558 \\
Cert. of Prison & -.147 & $-2.983 \mathrm{~b}$ & -.135 & $-2.775 \mathrm{~b}$ \\
Executions & & & & \\
Month t & .431 & .665 & .996 & .968 \\
Month t-1 & 1.112 & 1.525 & 2.957 & $2.636 \mathrm{~b}$ \\
Month t-2 & -.379 & -.521 & 1.004 & .888 \\
Month t-3 & -.440 & -.599 & -.443 & -.391 \\
Month t-4 & .792 & .980 & .405 & .344 \\
Month t-5 & .663 & .790 & 1.021 & .842 \\
Month t-6 & -.450 & -.512 & -.719 & -.583 \\
Month t-7 & 1.544 & $1.811 \mathrm{a}$ & .964 & .774 \\
Month t-8 & 1.262 & 1.430 & 1.168 & .971 \\
Month t-9 & 1.037 & 1.274 & .984 & .814 \\
Month t-10 & 2.198 & $2.534 \mathrm{~b}$ & 1.527 & 1.256 \\
Month t-11 & 1.653 & $1.869 \mathrm{a}$ & .494 & .384 \\
Month t-12 & .698 & .826 & .559 & .459 \\
Constant & 48.323 & 1.700 & 37.772 & 1.307 \\
R2 & .509 & $3.74 \mathrm{~b}$ & .455 & $3.01 \mathrm{~b}$ \\
\hline \hline
\end{tabular}

* For the unstandardized regression coefficients $(B), t$ values are reported; for the multiple $\mathrm{R}^{2}$ values, $\mathrm{F}$ values are reported.

$\mathrm{a}=\mathrm{p}<.05$

$\mathrm{b}=\mathrm{p}<.01$

negative, none are statistically significant, and one of the positive execution coefficients (for $\mathrm{t}-1$ ) is significant at the .05 level. 68 Also, in both analyses, the certainty of imprisonment, but not arrest, is significantly related to first-degree murders. ${ }^{69}$

The Durbin-Watson statistics reported in Table 5 indicate that the OLS estimates are not seriously biased due to first-order serial correla-

$68 \mathrm{~B}=2.713 ; \mathrm{t}=2.373$.

69 There is a high degree of correspondence between the number of monthly executions and the execution dummy variables with the simple $r$ coefficients ranging from .88 to .93 for the thirteen lag periods. 
TABLE 7

OLS: Number of MONTHLy Homicides Regressed Against LAGged Number of EXecutions, a LAGGed EXecution DumMY Variable, AND Other Selected Factors; Chicago, 1915-1921*

\begin{tabular}{|l|c|c|c|c|}
\hline \hline & \multicolumn{2}{c|}{ No. Executions } & \multicolumn{2}{c|}{ Execution } \\
\hline Independent Variable & \multicolumn{1}{c|}{$\mathrm{B}$} & $\mathrm{t} / \mathrm{F}$ & $\mathrm{B}$ & $\mathrm{t} / \mathrm{F}$ \\
\hline \hline Population Density & -.008 & $-2.669 \mathrm{~b}$ & -.007 & $-2.433 \mathrm{~b}$ \\
Public Assistance & -3.429 & -.941 & -3.485 & -.089 \\
Season & 1.531 & 1.369 & 1.366 & 1.194 \\
Cert. of Arrest & -.129 & $-2.419 \mathrm{~b}$ & -.143 & $-2.670 \mathrm{~b}$ \\
Cert. of Prison & -.338 & $-3.933 \mathrm{~b}$ & -.326 & $-4.001 \mathrm{~b}$ \\
Executions & & & & \\
Month t & .123 & .130 & 1.028 & .669 \\
Month t-1 & .399 & .379 & 2.340 & 1.433 \\
Month t-2 & -.906 & -.860 & .603 & .360 \\
Month t-3 & -1.162 & -1.061 & -1.343 & -.793 \\
Month t-4 & 1.213 & 1.029 & 1.755 & .997 \\
Month t-5 & .720 & .602 & .019 & .010 \\
Month t-6 & -.599 & -.479 & -2.209 & -1.193 \\
Month t-7 & 2.150 & $1.741 \mathrm{a}$ & 1.314 & .699 \\
Month t-8 & 2.120 & 1.659 & 1.374 & .768 \\
Month t-9 & 3.611 & $3.010 \mathrm{~b}$ & 4.076 & $2.223 \mathrm{a}$ \\
Month t-10 & 3.413 & $2.798 \mathrm{~b}$ & 3.032 & $1.716 \mathrm{a}$ \\
Month t-11 & 1.866 & 1.500 & .639 & .345 \\
Month t-12 & 1.119 & .928 & 1.455 & .805 \\
Constant & 172.193 & $3.572 \mathrm{~b}$ & 156.876 & $3.262 \mathrm{~b}$ \\
R2 & .428 & $2.70 \mathrm{~b}$ & .389 & $2.30 \mathrm{~b}$ \\
D.W. & 1.912 & & 1.715 & \\
\hline \hline
\end{tabular}

* For the unstandardized regression coefficients (B), $t$ values are reported; for the multiple $R^{2}$ values, $F$ values are reported.

$\mathrm{a}=\mathrm{p}<.05$

$\mathrm{b}=\mathrm{p}<.01$

tion. However, the possible bias resulting from higher order autocorrelation effects remains uncertain. To explore this question, lag periods as far back as t-12 months were explored and a significant second-order autocorrelation effect was detected. Table 6 reports re-estimated equations for first-degree murder correcting for the second-order autoregressive process.

This reanalysis does not significantly alter the pattern of findings from the OLS procedure. As before, a majority of the coefficients are positive when both the actual number of executions (10/13) and the execution dummy variable $(11 / 13)$ are considered. This analysis differs 


\section{TABLE 8}

CORC: Number of MONTHLy Homicides Regressed Against LaGged Number of EXecutions, a LagGed EXecution Dummy Variable, and Other Selected Factors; Chicago, 1915-1921*

\begin{tabular}{|l|r|c|c|c|}
\hline \hline & \multicolumn{2}{c|}{ No. Executions } & \multicolumn{2}{c|}{ Execution Dummy } \\
\hline \hline Independent Variables & \multicolumn{1}{c|}{$\mathrm{B}$} & $\mathrm{t} / \mathrm{F}$ & $\mathrm{B}$ & $\mathrm{t} / \mathrm{F}$ \\
\hline Population Density & -.004 & $-1.858 \mathrm{a}$ & -.003 & -1.294 \\
Public Assistance & -.036 & -.011 & 3.145 & .874 \\
Season & 2.062 & $1.690 \mathrm{a}$ & 2.139 & $1.876 \mathrm{a}$ \\
Cert. of Arrest & -.206 & $-4.235 \mathrm{~b}$ & -.230 & $-3.428 \mathrm{~b}$ \\
Cert. of Prison & -.171 & $-2.890 \mathrm{~b}$ & -.115 & -1.614 \\
Executions & & & & \\
Month t & .338 & .392 & 2.433 & $1.920 \mathrm{a}$ \\
Month t-1 & .248 & .248 & 3.782 & $2.641 \mathrm{~b}$ \\
Month t-2 & -1.394 & -1.405 & 1.518 & 1.034 \\
Month t-3 & -2.046 & $-2.033 \mathrm{a}$ & -1.672 & -1.158 \\
Month t-4 & .117 & .114 & .606 & .393 \\
Month t-5 & -.388 & -.370 & -.545 & -.317 \\
Month t-6 & -1.573 & -1.411 & -2.734 & -1.487 \\
Month t-7 & 1.096 & .959 & .120 & .065 \\
Month t-8 & 1.306 & 1.133 & .664 & .395 \\
Month t-9 & 2.785 & $2.576 \mathrm{~b}$ & 2.156 & 1.278 \\
Month t-10 & 3.159 & $2.651 \mathrm{~b}$ & 1.510 & .914 \\
Month t-11 & 1.896 & 1.534 & -.752 & -.437 \\
Month t-12 & .534 & .470 & -.141 & -.091 \\
Constant & 96.273 & $3.293 \mathrm{~b}$ & 91.596 & $2.037 \mathrm{a}$ \\
R2 & .491 & $3.48 \mathrm{~b}$ & .486 & $3.41 \mathrm{~b}$ \\
\hline
\end{tabular}

* For the unstandardized regression coefficients (B), $t$ values are reported; for the multiple $R^{2}$ values, $F$ values are reported.

$\mathrm{a}=\mathrm{p}<.05$

$\mathrm{b}=\mathrm{p}<.01$

only in that the number of executions is positively and significantly associated with the number of first-degree murders for three lag periods ( $t-7$, $t-10, t-11)$ rather than just the one $(t-10)$ as found in the OLS analysis. Certainty of imprisonment is again significantly associated with firstdegree murders, as it is in the OLS analysis.

To further explore the possible delayed deterrent effect of executions, Table 7 reports the results of the analysis where the number of monthly criminal homicides is regressed against both execution variables lagged from month $t$ through month $t-12$. This analysis also does not support the deterrence argument for capital punishment. Both cer- 
tainty of arrest and certainty of imprisonment are significantly, and negatively, associated with the number of homicides, but none of the negative execution coefficients are statistically significant. As before, the vast majority of the execution coefficients are positive (21/26). They are statistically significant for three lag periods for the number of executions $(t-7, t-9, t-10)$, and for two lag periods for the execution dummy variable $(\mathrm{t}-9, \mathrm{t}-10)$.

Again, to explore for possible autocorrelation effects, the analysis reported in Table 7 for homicide was repeated considering the possibility of autocorrelation processes ranging from t-1 through t-12 months. Surprisingly, and for reasons that are not clear, a significant ninth-order autocorrelation effect was detected when both the number of executions and the execution dummy factor were considered.

Table 8 reports the results of the analysis where a Cochrane-Orcutt type of iterative procedure was used to correct for the ninth-order autocorrelation effect. Comparison of the OLS and the CORC estimates reported in Tables 7 and 8, respectively, reveals a similar pattern of findings. When the number of executions is considered, most $(9 / 13)$ of the coefficients are again positive and two $(t-9, t-10)$ are statistically significant at the .01 level. Interestingly, however, one of the four negative execution coefficients $(t-3)$ is also statistically significant $(p<.05)$ in the GORC analysis.

When the execution dummy variable is considered, a majority $(8 / 13)$ of the execution coefficients are also positive, and two (months $t$ and $t-1)$ are statistically significant. This analysis also continues to suggest the importance of the deterrent effect of arrest and imprisonment.

\section{RESULTS OF A NONLINEAR ANALYSIS}

The results up to this point clearly do not support the deterrence hypothesis for capital punishment. Throughout the analysis, executions and killings are generally positively associated, and significantly so in some cases. In contrast, in only one isolated case-Table 8-is there a significant inverse relationship between executions and killings. The possibility exists, however, that these generally negative findings are the result of improperly specifying the functional form of the relationship between executions and the dependent variables. We have considered only the possible linear relationship between executions and killings. It may be that the actual form of the relationship between these two factors is nonlinear. Unfortunately, we can only speculate about this because proponents of the deterrence theory are silent on the question of 
the form of the relationship between executions and killings. ${ }^{70}$ Typically, proponents simply argue that executions have a significant deterrent effect on murder.

In exploring this question, previous death penalty investigators have examined one of three models of the relationship between executions and killings: (1) a linear additive model, such as the one used here; ${ }^{71}$ (2) a semi-log model, where the data for the dependent variable are transformed; ${ }^{72}$ or (3) a double-log model, where both the figures for the homicide and predictor variables are transformed..$^{73}$ These three models have generally produced very consistent results. With but two noted exceptions, ${ }^{74}$ neither a significant linear nor nonlinear relationship has been found between executions and homicides. Ehrlich, for example, in his time-series analysis of nationally aggregated execution and homicide data ${ }^{75}$ found a statistically significant negative relationship between these two factors when a double-log model was used, but a nonsignificant relationship when the execution and homicide data were examined in their original form with a linear model.

To test for a possible nonlinear relationship between executions and murders in Chicago, natural log transforms were performed on the murder and homicide dependent variables and the above analysis (Tables 28) was repeated. ${ }^{76}$ Table 9 reports the results of the nonlinear analysis where the transformed monthly murder and homicide data and both execution variables are considered. This analysis is simply a replication of that reported in Tables 2 and 3 , but with the consideration of transformed murder and homicide figures.

70 See, e.g., W. Berns, For Capital Punishment (1979); E. Van den HaAG, Punishing CRIMINALS, supra note 47; Lehtinen, supra note 52; van den Haag; On Deterrence, supra note 47.

71 Bowers \& Pierce, supra note 17; Passell \& Taylor, The Deterrence Controversy: A Reconsideralion of Time-Series Evidence, in Capital Punishment in the United States 359 (H. Bedau \& C. Pierce eds. 1976).

72 Bailey, supra note 10; Bailey, Death Penalty for Murder in Ohio, supra note 21; Bailey, Death Penally for Murder in Califormia, supra note 21; Bailey, Death Penalty in North Carolina, supra note 21.

73 Erlich, supra note 14; Ehrlich, supra note 20.

74 Ehrlich, supra note 14; Yunker, supra note 16.

75 Ehrlich, supra note 14 .

76 A semi-log model was used here, not a double-log function as in the Ehrlich study, because of the number of months $(65 / 84)$ in the Chicago time series where there were no executions. We do not view this as a major limitation, however. First, and obviously, the log of zero cannot be taken. Second, when data points have zero values that are theoretically meaningful (in this case, no executions), it makes no sense to follow Ehrlich's practice of arbitrarily substituting non-zero values for zeroes so that the data can be log-transformed. Third, there is no a priori reason to expect that a double-log function provides a better test of the deterrent effect of executions than a semi-log model. In short, a semi-log model seems like a reasonable alternative to consider, although we well recognize that it is just one of a number of nonlinear functions that might be explored. Without some theoretical rationale, however, the mass exploration of alternative nonlinear functions would simply be a fishing expedition. 
TABLE 9

OLS: Log Number of Monthly First Degree Murders and Homicides Regressed Against Number of Executions, an Exegution Dummy Variable, and Other Selected Factors; Chicago, 1915-1921*

\begin{tabular}{|l|c|c|c|c|c|c|c|c|}
\hline \hline \multicolumn{4}{c}{ No. Executions } & \multicolumn{3}{c|}{ Execution Dummy } & \multicolumn{4}{c|}{ No. Executions } & \multicolumn{4}{c|}{ Execution Dummy } \\
\hline Independent Variable & $\mathrm{B}$ & $\mathrm{t} / \mathrm{F}$ & $\mathrm{B}$ & $\mathrm{t} / \mathrm{f}$ & $\mathrm{B}$ & $\mathrm{t} / \mathrm{F}$ & $\mathrm{B}$ & $\mathrm{t} / \mathrm{F}$ \\
\hline \hline Population Density & .000 & 1.478 & .000 & 1.383 & -.000 & $-1.963 \mathrm{a}$ & -.000 & $-2.291 \mathrm{a}$ \\
Public Assistance & .338 & .902 & .332 & .884 & -.042 & -.194 & -.046 & -.216 \\
Season & .017 & .154 & .018 & .166 & .058 & .905 & .061 & .936 \\
Cert. of Arrest & -.009 & $-1.674 \mathrm{a}$ & -.009 & $-1.691 \mathrm{a}$ & -.010 & $-2.934 \mathrm{~b}$ & -.011 & $-2.993 \mathrm{~b}$ \\
Cert. of Prison & -.014 & $-1.826 \mathrm{a}$ & -.014 & $-1.855 \mathrm{a}$ & -.013 & $-3.196 \mathrm{~b}$ & -.013 & $-3.295 \mathrm{~b}$ \\
Executions & .002 & .018 & .031 & .225 & -.025 & -.490 & .032 & .392 \\
Constant & .095 & .365 & 1.064 & .426 & 6.045 & $5.448 \mathrm{~b}$ & 6.357 & $5.664 \mathrm{~b}$ \\
R2 & .193 & $3.06 \mathrm{~b}$ & .193 & $3.07 \mathrm{~b}$ & .255 & $4.39 \mathrm{~b}$ & .254 & $4.37 \mathrm{~b}$ \\
D.W. & 2.064 & & 2.082 & & 1.748 & & 1.746 & \\
\hline
\end{tabular}

* For the unstandardized regression coefficients $(B), t$ values are reported; for the multiple $\mathrm{R}^{2}$ values, $\mathrm{F}$ values are reported. $a=p<.05$

$\mathrm{b}=\mathrm{p}<.01$ 
The results for the sanction variables exactly parallel the earlier findings. For first-degree murder, there is a nonsignificant positive relationship between both execution measures and the dependent variable. For homicide, the coefficients are mixed in sign for the two execution variables, but regardless of their sign, none are statistically significant. In contrast, the certainty of arrest and imprisonment are negatively, and significantly, associated with both types of killings when each execution measure is considered.

To test for problems of serial correlation, the analysis reported in Table 9 was repeated with autocorrelation processes being explored with lags as far back as month t-12. A significant fifth-order autocorrelation effect was detected for murder, and a significant fourth-order autocorrelation effect for homicide, but corrections for these effects do not alter the results for the sanction variables. There remains only a low-positive or a low-negative, and chance, relationship between executions and killings, and a significant negative association between the certainty of arrest and imprisonment and both dependent variables.

Table 10 reports the results of the analysis where the possible delayed effect of executions is considered using the transformed murder and homicide data. This is a replication of the analysis reported in Tables 5 and 7 but with alternative transformed murder and homicide figures.

For both types of offenses, the findings are similar to the previous linear analysis. For murder I, none of the negative execution coefficients are statistically significant. In contrast, the number of murders is positively and significantly associated with the number of executions for one lag period (month $t-1)$. Similarly, for homicide, a minority of the execution coefficients are negative and none are statistically significant. Also contrary to the deterrence hypothesis, homicides are positively and significantly associated with the number of executions for four lag periods $(t-7, t-9, t-11, t-12)$ and the execution dummy variable for two lag periods $(t-9, t-10)$. The lag periods for the significant execution results parallel the linear analysis. Also consistent with the linear analysis, Table 10 continues to provide evidence of the deterrent effect of arrest and imprisonment for both types of killings.

The Durbin-Watson values reported in Table 10 suggest that the tratios for the execution and other variables are not seriously biased due to first-order serial correlation, but higher-order autocorrelation problems remain a possibility. Indeed, examination reveals a significant second-order autocorrelation effect in the murder I analysis when each execution variable is considered, and a significant fourth-order autocorrelation effect in the homicide analysis for both execution variables. 
TABLE 10

OLS: Log Number of Monthly First Degree Murders and Homicides Regressed Against Lagged Number of Executions, an Execution Dummy Variable, and Other Selected Factors; Chicago, 19151921.*

\begin{tabular}{|c|c|c|c|c|c|c|c|c|}
\hline \multirow[b]{3}{*}{ Independent Variable } & \multicolumn{4}{|c|}{ First Degree Murder Results } & \multicolumn{4}{|c|}{ Homicide Results } \\
\hline & \multicolumn{2}{|c|}{ No. Executions } & \multicolumn{2}{|c|}{ Execution Dummy } & \multicolumn{2}{|c|}{ No. Executions } & \multicolumn{2}{|c|}{ Execution Dummy } \\
\hline & B & $t / F$ & B & $t / F$ & B & $t / F$ & B & $t / F$ \\
\hline Population Density & -.000 & -.443 & -.000 & -.415 & -.005 & $-2.629 b$ & -.000 & $2.360 \mathrm{a}$ \\
\hline Public Assistance & .243 & .657 & .224 & .564 & -.281 & -1.321 & -.287 & -1.242 \\
\hline Season & -.028 & -.247 & -.030 & -.259 & .068 & 1.042 & .057 & .842 \\
\hline Cert. of Arrest & -.008 & -1.553 & -.010 & $-1.818 a$ & -.010 & $-3.138 b$ & -.011 & $-3.314 b$ \\
\hline Cert. of Prison & -.017 & $-1.986 a$ & -.017 & $-2.076 a$ & -.019 & $-3.886 b$ & -.019 & $-3.903 b$ \\
\hline \multicolumn{9}{|l|}{ Executions } \\
\hline Month t & .086 & .894 & .161 & 1.031 & .001 & .026 & .048 & .525 \\
\hline Month t-1 & .138 & 1.295 & .320 & $1.924 \mathrm{a}$ & .017 & .280 & .102 & 1.055 \\
\hline Month t-2 & -.168 & -1.574 & -.039 & .227 & -.079 & -1.268 & -.015 & -.154 \\
\hline Month $t-3$ & -.081 & -.729 & -.058 & -.336 & -.070 & -1.094 & .099 & -.989 \\
\hline Month t-4 & .122 & 1.015 & .051 & .287 & .064 & .932 & .069 & .659 \\
\hline Month t-5 & .089 & .736 & .199 & 1.080 & .041 & .592 & .016 & .149 \\
\hline Month t- 6 & -.164 & -1.295 & -.146 & -.777 & -.063 & -.870 & -.150 & -1.367 \\
\hline Month t-7 & .183 & 1.462 & .168 & .877 & .138 & $1.914 \mathrm{a}$ & .094 & .844 \\
\hline Month $t-8$ & .131 & 1.006 & .095 & .520 & .119 & 1.592 & .068 & .641 \\
\hline Month t-9 & .113 & .926 & .134 & .719 & .209 & $2.996 \mathrm{~b}$ & .254 & $2.341 \mathrm{a}$ \\
\hline Month 1-10 & .217 & $1.748 \mathrm{a}$ & .202 & 1.124 & .197 & $2.768 \mathrm{~b}$ & .186 & $1.775 a$ \\
\hline Month $\mathrm{t}-11$ & .131 & 1.036 & -.014 & -.074 & .140 & $1.927 \mathrm{a}$ & .087 & .789 \\
\hline
\end{tabular}




\section{TABLE 10}

OlS: Log Number of Monthly First Degree Murders and Homicides Regressed Against Lagged Number of Executions, an Execution Dummy Variable, and Other Selected Factors; Chicago, 19151921.*

\begin{tabular}{|c|c|c|c|c|c|c|c|c|}
\hline \multirow[b]{3}{*}{ Independent Variable } & \multicolumn{4}{|c|}{ First Degree Murder Results } & \multicolumn{4}{|c|}{ Homicide Results } \\
\hline & \multicolumn{2}{|c|}{ No. Executions } & \multicolumn{2}{|c|}{ Execution Dummy } & \multicolumn{2}{|c|}{ No. Executions } & \multicolumn{2}{|c|}{ Execution Dummy } \\
\hline & $\mathbf{B}$ & $t / F$ & B & $t / F$ & B & $\mathrm{t} / \mathrm{F}$ & B & $t / F$ \\
\hline Month t-12 & -.000 & -.002 & -.058 & -.318 & .066 & .940 & .105 & .977 \\
\hline Constant & 5.302 & 1.083 & 5.208 & 1.064 & 12.059 & $4.293 \mathrm{~b}$ & 11.198 & $3.929 \mathrm{~b}$ \\
\hline $\mathrm{R}^{2}$ & .361 & $2.04 \mathrm{a}$ & .316 & 1.67 & .457 & $3.046 \mathrm{~b}$ & .401 & $2.41 \mathrm{~b}$ \\
\hline D.W. & 2.108 & & 2.110 & & 2.083 & & 1.894 & \\
\hline
\end{tabular}

* For the unstandardized regression coefficients $(B), t$ values are reported; for the multiple $\mathrm{R}^{2}$ values, $\mathrm{F}$ values are reported. $\mathrm{a}=\mathrm{p}<.05$

$b=p<.01$ 
When the four models presented in Table 10 are re-estimated correcting for autocorrelation, the results are equally inconsistent with the deterrence hypothesis. Again, only a minority of the execution coefficients are negative, and none are statistically significant for either firstdegree murder or homicide. For murder I, three of the positive execution coefficients are statistically significant $(t-1, t-7, t-10)$ and one of the execution dummy coefficients is significant $(t-1)$. For homicide, only one of the execution dummy coefficients is statistically significant (t-9). Four of the coefficients are statistically significant when the number of executions is considered ( $t-8, t-9, t-10, t-11)$. As contrary as these findings are to the deterrence hypothesis for executions, the results of this reanalysis are quite consistent with the hypothesized deterrent effect of arrest and imprisonment.

To briefly summarize, for the period under investigation, we find no evidence that capital punishment provided an effective deterrent to first-degree murder in Chicago. Where the deterrence model poses a significant inverse relationship between executions and capital killings, our analysis shows that these two factors are most commonly positively associated. This pattern holds for the linear and nonlinear models for both execution measures, and also when the majority of the execution lag periods are considered.

When a more general category of homicide is considered, the results are very similar. Although the findings differ somewhat for the linear and nonlinear models, the basic pattern is the same, whether the actual number of executions or the execution dummy variable is considered. Contrary to the deterrence hypothesis, executions are more typically associated with a higher rather than a lower number of criminal homicides. This positive relationship is statistically significant for some lag periods for either or both of the execution measures in the linear (months $t, t-1, t-7, t-9, t-10$ ) and nonlinear analysis (months $t-7, t-8, t-9$, $t-10, t-11)$.

\section{E. THE BRUTALIZATION HYPOTHESIS}

On balance, these findings for both murder and homicide seem consistent with Bowers and Pierce's claim 77 that the effect of executions is to increase, not decrease, killings. ${ }^{78}$ This argument-that capital pun-

77 Bowers \& Pierce, Deterrence or Brutalization, supra note 21.

78 Rather than indicating a brutalization effect, the generally positive association between executions and both types of killings might be interpreted as evidence that the level of murder has a positive effect on the "demand" for executions. Brier \& Fienberg, supra note 17, at 179; Friedman, supra note 17 , at 69 . To illustrate, in Community A, which has a high murder rate, fear and public outrage may result in a higher number of convicted murderers being sentenced to death and executed than in Community B, where the murder rate is low and is not 
ishment, because of its "brutalization effect," actually contributes to the murder problem - has a long history in the criminology literature. ${ }^{79}$ Like the deterrence theory, however, the "brutalization" hypothesis is not well developed theoretically. For example, this body of literature is virtually silent on such basic matters as the magnitude of the positive relationship to expect between executions and resulting homicides, and the nature of the temporal relationship-possible lag-between executions and resulting homicides. Proponents of the brutalization hypothesis are generally no more specific about these two matters than to argue that executions encourage more murders than they prevent and that the impact of executions is probably immediate and rather short-term. ${ }^{80}$

With only such a general theoretical framework to test against, it is not altogether clear whether our findings should be interpreted as supporting the brutalization argument. For example, the brutalization theory hypothesizes a positive relationship between executions and killings, and this pattern generally holds for our data. However, for both firstdegree murder and total criminal homicides, the execution coefficients are negative for some lag periods.

Second, the size of the positive execution coefficients vary considerably by lag period, and this variation does not correspond to what the brutalization argument might lead us to expect. Whereas one might predict that the impact of executions on killings would be immediate and short-term, the execution coefficients more often tend to be statistically significant, and slightly larger in size, for the more extended lag

seen as such a serious problem. Similarly, within the same community over time, changes in the level of murder may influence the demand for executions.

While the "demand for executions" hypothesis is plausible and could produce a positive relationship between executions and killings, this argument cannot account for our findings for Chicago. Because of the typical delay of at least one year between the commission of a murder, conviction, and execution, Bailey, supra note 10, at 1314-15; Ehrlich, supra note 14, at 407, the demand hypothesis cannot explain the positive relationship between executions and killings when both factors are examined for month $t$ (Tables 2, 3,4 and 9). Similarly, it makes no sense to argue that the level of homicides during month $t$ could have influenced the level of monthly executions during the previous one-year period (Tables 5, 6, 7, 8 and 10).

79 C. Beccaria, On Crimes and Punishments (1764); L. Hamilton, Memoirs, SPeEches AND Writings OF Robert Rantoul, JR. 474 (1854); Bowers \& Pierce, Delerrence or Brutalization, supra note 21; Diamond, Murder and the Death Penally: A Case Report, in CAPItal Punishment in the United States 445 (1976); Glaser, Capital Punishment-Deterrent or Stimulus to Murder? Our Unexamined Deaths and Penalties, 10 U. TOL. L. REv. 317 (1979); Graves, A Doctor Looks at Capital Punishment, 10 J. LOMA LiNDA U. SCH. MED. 137 (1956); Marx, Capital Punishment, reprinted in L. FeURER, KARL MARX AND FRIEdRIGH ENGELS, BAsic Writings in Politics and Philosophy 485 (1959); Solomon, Capital Punishment as Suicide and as Murder, in Capital Punishment in the United States, supra, at 432.

80 Bowers \& Pierce, Deterrence or Brutalization, supra note 21. The fact that murder rates are generally higher in death penalty than abolition states is frequently cited by proponents of the brutalization argument as evidence indicating the long-term and cumulative effect of capital punishment. 
periods of months $\mathrm{t}-6$ through $\mathrm{t}-12$. That is, for some unknown reason, it appears that executions had a more substantial delayed than immediate brutalization effect on Chicago first-degree murders and criminal homicides.

Finally, the results vary somewhat depending upon whether the actual number of executions or the execution dummy variable is considered. For murder $\mathrm{I}$, the dummy variable for month $\mathrm{t}-1$ is positively and significantly associated with the number of killings, but this pattern does not hold for the actual number of executions lagged by one month. In contrast, first-degree murders are significantly and positively associated with the actual number of executions when some more distant lag periods are considered (months $t-7, t-10, t-11$ ), but this pattern does not hold for the dummy execution variable for these longer time lags. Similarly, but to a lesser extent, the findings for the two execution measures are also not uniform by lag period when total criminal homicides are examined.

In light of these mixed findings, one might conclude that this analysis also provides no support for the brutalization hypothesis for capital punishment. This conclusion would be consistent with Sellin's claim that "the death penalty - in law or practice-does not influence homicide death rates,"81 and the findings of a number of studies showing that executions and murder are largely independent factors. As discussed above, however, most previous investigations are not without serious limitations, some of which we have attempted to overcome in this analysis. In addition, the dominant pattern of a positive relationship between executions and killings found throughout the analysis cannot be ignored.

If executions and killings were, indeed, simply random events, we would expect (1) no association between these two factors, or (2) a slight positive or negative relationship between these two factors, due to sampling error, with the positive and negative execution coefficients being roughly equal in number, and averaging to zero when summed. This hypothetical random pattern of executions and killings does not fit the Chicago data. To the contrary, when the findings for first-degree murder are combined from Tables 5, 6 and 10, fifty-eight of seventy-eight (74.4\%) of the execution coefficients are positive. Similarly, for criminal homicide, fifty-nine of seventy-eight (75.6\%) of the execution coefficients are positive. For both first-degree murder and homicide the number of positive execution coefficients is significantly different from chance at beyond the .01 level.

Furthermore, the observed positive and negative execution coeff- 
cients do not sum to zero for either type of killing for either of the execution measures. When first-degree murder and the number of executions are considered over the thirteen lag periods (Table 5), the execution coefficients sum to +7.734 . The execution dummy coefficients sum to +7.714 for the thirteen lag periods for murder I. For homicide (Table $7)$, when the number of executions are considered, the coefficients sum to +14.067 over the thirteen lag periods. For homicide for the dummy execution variable, the thirteen coefficients sum to +14.083 . These imbalances in a positive direction are beyond what one would expect if executions and killings were simply random events.

\section{Conclusion}

It is conceivable that there is at least some degree of merit to both the deterrence and brutalization arguments for capital punishment. To some degree, and for some segment of the population, executions may deter killings. Conversely, to some degree, and for some other segment of the population, executions may encourage killings. In other words, at the same time that executions may encourage some persons to kill, they may discourage others from committing murder.

To differentiate the possible deterrent and brutalization effects of capital punishment, it is necessary to (1) develop independent indicators of the deterrent and brutalization effects of executions rather than simply rely upon the overall number or rate of killings as a dependent variable, and/or (2) try to identify sub-segments of the population that are differentially affected by executions due to deterrence and brutalization, and then examine their differential involvement in murder. Due to data constraints and the crude nature of both the deterrence and brutalization arguments, such an analysis is not possible at this time. Despite this limitation, however, one can still legitimately ask: What is the net effect of executions on killings? Overall, is the effect of executions to increase or decrease killings? And, in the context of the current study, was the effect of executions to increase or decrease Chicago killings?

In line with the brutalization argument, this analysis suggests that the net effect of executions may well have been to increase, not decrease, Chicago first-degree murders and total criminal homicides. This finding is consistent with a number of early and more recent investigations of the brutalization effect of capital punishment in this country ${ }^{82}$ and is only partially at odds with one study. ${ }^{83}$ In addition, our findings are

82 Bowers \& Pierce, Deterrence or Brutalization, supra note 21; Graves, supra note 79; King, supra note 21; Savitz, A Study in Capital Punishment, 49 J. CRIM. L. CRIMINOLOGY \& POLICE Scr. 338 (1958).

83 Phillips reported that the initial effect of the highly publicized execution of two dozen notorious London murderers (1875-1905) was to reduce killings, which was then balanced by 
consistent with the fact that not a single reputable study has yet shown that capital punishment is an effective deterrent to murder. Deterrence may indeed be an indispensable cornerstone of our criminal justice system, but when it comes to murder and capital punishment, this theory and justification for punishment lacks empirical support.

an unusual increase in murders, for a net effect of close to zero. Phillips, The Deterrent Effect of Capilal Punishment: New Evidence on an Old Controversy, 86 AM. J. Soc. 139, 147 (1980). Because Phillips chose to examine only very atypical killers whose executions received inordinate media attention, it remains unclear how well his findings can be generalized to more typical offenders and executions, even in London. Furthermore, Phillips well recognizes that, for a variety of theoretical and methodological reasons, his findings may not be generalizable to contemporary America. 